\title{
Strategies for Increasing the Role of Family Medicine in Mexican Health Care Reform
}

\author{
José Manuel Ramírez Aranda, MD, Dr med, Chris van Weel, MD, PhD, \\ and Felicity Goodyear-Smith, MBChB, MD
}

There is little or no role for primary care and family medicine in current health reforms in Mexico. However, robust evidence shows that primary care helps prevent morbidity and mortality and increases health equity. Mexico has participated in several international meetings sponsored by the World Organization of National Colleges, Academies and Academic Associations and the North American Primary Care Research Group that are aimed at increased understanding of national health systems and the need to strengthen primary care for improved health outcomes. From 1 of these meetings the Cancún Manifesto emerged, with a strategic plan to increase the stature and impact of the Mexican College of Family Physicians (COLMEXAC) in strengthening primary care in Mexico. We aim to describe this strategic plan and discuss its early implementation, and for this account to serve as a possible formula for other countries. The 5 specific strategies discussed are 1) the need for consensus on the leading role of the Mexican family physician in the national health system; 2) health ecology research; 3) to improve the perception of patients about the benefits of primary care and family medicine; 4) to organize meetings of health providers, users, and other stakeholders; and 5) to promote the professionalization of COLMEXAC as a legal entity. (J Am Board Fam Med 2017;30:843-847.)

Keywords: Access to Health Care, Delivery of Health Care, Health Care Reform, Health Policy, Mexico, Universal Coverage

Mexico is currently undergoing difficult times politically, socially, and economically. The government has introduced reforms aimed at improving health care delivery for the entire population, but

This article was externally peer reviewed.

Submitted 6 February 2017; revised 12 July 2017; accepted 22 July 2017.

From the Department of Family Medicine, Hospital Universitario Dr. Jose Eleuterio Gonzalez y Facultad de Medicina, Universidad Autonoma de Nuevo Leon, Monterrey, Mexico (JMRA); Department of Primary and Community Care, Radboud University Medical Center, Nijmegen, The Netherlands and Department of Health Services and Policy, Australian National University, Canberra, Australia (CvW) Department of General Practice \& Primary Health Care, University of Auckland, Auckland, New Zealand (FGS).

Funding: none.

Conflict of interest: none declared.

Prior presentation: Symposium Primary Health Care Policy Implementation, WONCA World Conference Rio de Janeiro, Brazil, November 02, 2016.

Corresponding author: José Manuel Ramírez Aranda, MD, Dr med, Departamento de Medicina Familiar, Edificio Rodrigo Barragán, Hospital Universitario "Dr. José E. González", Av. Madero y Gonzalitos s/n, Colonia Mitras Centro, Monterrey, Nuevo León, México CP 64460 (E-mail sersabe2010@gmail.com). to date these have not been as successful as hoped. Reasons for this include limitations in state and federal capacity to implement the changes, tensions in federal-state relations, inadequate information systems, political influences, and financial resources used for unauthorized expenditures at the state level. ${ }^{1}$ Robust evidence has demonstrated that primary care helps prevent morbidity and mortality, and that in contrast with specialist care, it is associated with increased health equity in both crossnation and within-nation studies. ${ }^{2}$ Effective, efficient, and equitable health care is related to government-controlled universal primary health coverage with little or no required copayments, equitable distribution of resources, and comprehensive services, not to the wealth of the country or the total number of health personnel. ${ }^{3}$

The Seguro Popular (Popular Health Insurance) is the insurance-based reform introduced to provide funding for health care for families, most of them poor, and previously excluded from health insurance. ${ }^{4}$ However, due to a number of factors, 
including parallel vertical funding structures that increased administrative costs, and the lack of coordinating primary care services, Popular Health Insurance has failed to deliver adequate care. ${ }^{5}$ In the United States, the Affordable Care Act expanded the number of people gaining health insurance coverage, with a focus on strengthening primary care services, but this has not always equaled to their receiving improved and equitable access to care. ${ }^{6}$ Fee-for-service charges may still serve as a barrier $^{7}$, and adequate primary care infrastructure is paramount. ${ }^{8}$

Herein, we argue that Mexico needs universal primary health care to address inequities and improve the quality of services for the most underprivileged populations. Such health care reform has not been formally announced, and the health system is currently facing serious threats including budgetary cuts. There is little or no role for primary care and family medicine in the current Mexican health reforms. Primary care in Mexico needs to be strengthened.

The World Health Organization recognizes the importance of primary care in providing universal health coverage and reducing social disparities in health. ${ }^{9}$ A number of countries, including Australia, Denmark, and New Zealand, have experienced transformations in their health systems in past decades through the implementation of specific strategies and have shared information about these reforms. ${ }^{10,11}$ The World Organization of National Colleges, Academies and Academic Associations of General Practitioners/Family Physicians (WONCA), and the North American Primary Care Research Group (NAPCRG), are facilitating the exchange of experiences among countries in the implementation of primary health care as the foundation of their health systems. ${ }^{12,13}$ Although health systems are different, strategies can be adapted and modified in other countries.

Mexico has participated in several WONCA and NAPCRG meetings, with the aim of reaching a better understanding of the health system and increasing awareness of all stakeholders (primary care health professionals, policy makers, employers and patients) of the need for change. ${ }^{5,13,14}$ In 2014 a NAPCRG preconference analyzed the Mexican health system, its elements, characteristics, strengths, and weaknesses to identify opportunities for improvement. ${ }^{13}$ Identified strengths include effective universal vaccination, increasing life expectancy, declining ma- ternal mortality, and increasing health coverage reflected in greater access to the system. However, large inequities remain, with compromised efficiency, heterogeneous health services unequal in their implementation, fragmentated health services, a lack of intersectoral coordination ${ }^{15}$, and a high percentage of out-of-pocket expenses (greater than $30 \%, 1$ of the highest in the Organisation for Economic Co-operation and Development). ${ }^{16}$

Primary care is minimal in the Mexican health system, predominantly accessed only through public health institutions. The role of the family physician is distorted by institutional demands that prioritize the generation of data over the provision of high-quality care. This scenario represents the ideal justification for implementing the efforts proposed by WONCA and NAPCRG in Mexico in the proposed transformation of the health system. ${ }^{17} \mathrm{To}$ develop this further, and to make policy makers aware of the research evidence of the leading role primary care plays in robust functioning health systems ${ }^{18}$, a second preconference was held at the 43rd NAPCRG conference in 2015. ${ }^{5}$ Ten researchers-leaders from the Mexican College of Family Medicine, (COLMEXAC) convened to design strategies to strengthen primary care.

The aim of this article is to describe the strategic plan developed by COLMEXAC to increase its stature and impact within the health policy realm in Mexico and discuss its early implementation. This account may serve as a possible model for other countries.

\section{COLMEXAC Strategic Plan}

COLMEXAC has 2 central aims:

1. To emphasize the need for primary health care policies and implementation practices in Mexico, primarily to decision makers, and

2. To inform Mexican leaders of the need to develop skills in primary care research.

To assist in achieving these goals, a number of actions were undertaken. A statement was generated reflecting the role that COLMEXAC can play in developing a health system oriented toward universal health care, known as the Cancún Manifesto. ${ }^{14}$ This document identified that primary health care must be the model adopted to improve the health of the population; that COLMEXAC 
must be proactive in the future implementation of the Mexican health system reform; that all health institutions must establish an agreement to participate in these reforms, and that engagement must be sought with all stakeholders involved in health care. The dissemination of this Manifesto included its publication in Spanish in the peer-reviewed journal, Annals of Family Medicine ${ }^{14}$, and in English on the NAPCRG Web site. ${ }^{19}$

Specific strategies outlined by the Cancún Manifesto and a subsequent call to action follow below.

\section{Consensus on the Leading Role of the Mexican Family Physician in the National Health System}

The Cancún Manifesto calls for consensus regarding the leading role of the Mexican family physician in the national health system. This requires increased visibility of family physicians and acknowledgment of their specialty competencies, their scope of action, their skills and abilities, and how they fit into the Mexican health system. This definition has been achieved in parts of Europe. ${ }^{20}$ An inevitable consequence would be to demonstrate the inconsistency between the postulates that are the foundation of the practice of family medicine according to Barbara Starfield ${ }^{18}$, and the competencies they use as family physicians in institutional practice. Currently, Mexican decision-makers and society as a whole ignore the role of the family physician, and consider other medical specialists as more comprehensive and better trained.

\section{Health Ecology Research}

The need to gain knowledge about the provision of health services in Mexico through research on the ecology of health care was identified. The seminal study by White et $\mathrm{al}^{21}$ showed over a period of 1 month the use of health services by the population and the proportion of individuals who report 1 or more illnesses, who go to the doctor, who are hospitalized, and who are referred to a university hospital. This model has been replicated in many countries including the United States ${ }^{22}$ and Tai$\operatorname{wan}^{23}$, and illustrates the high utilization of primary-care services by the population and the discrepancy between the allocation of financial resources to large highly specialized tertiary care centers that serve $1 \%$ of the population or less, versus $85 \%$ served in primary-care centers. In Mexico, public-health expenditures have gone mainly to the costly construction of regional and highly specialized hospitals rather than to strengthen primary care. $^{24}$

Sound research on the Mexican health system and the way health provision is distributed in all levels of care through access and analysis of data from heath institutions is proposed. This aims to replicate or adapt ecology health care research studies already developed in the United States and other countries. ${ }^{25}$ This might help persuade decision makers to strengthen the presence and position of primary care as a fundamental pillar of the health system. This is challenging because research has yet to investigate the use of health care with the model of ecology in a publicly funded health system. ${ }^{26}$

\section{Improve Patient Perception about the Benefits of Primary Care and Family Medicine}

Improving the perception of Mexican patients about the benefits of primary care and family medicine is important, and this would dignify the work of the family physician. A concerted action is urgently needed for the relevant individuals, associations, and family physician colleges to make family medicine visible, and to redefine the image of the doctor away from the belief of one who only refers patients to traditional specialists. Family physicians' capability to manage more than $85 \%$ of current health problems, including chronic degenerative diseases and increasing multimorbidity, must be emphasized and demonstrated. The "positive things" that the family physician is capable of doing should be displayed through a media campaign on patient's testimonies, videos, and academic sessions shared with other specialists. The publicity campaign should include access to news media, online communications, associations, and other outreach activities to reach not only patients, but also employers, policy makers, and other stakeholders across the country to recognize and support the value of family medicine and primary care. The proposed strategies can be part of a call for testimonials, rewarding the best which could be published (keeping the anonymity of doctor and patient) in medical journals as well as social media. 


\section{Organize Meetings of Health Providers, Users, and Other Stakeholders}

The Cancún Manifesto advocated that meetings and discussion forums should be convened to define the role of family physicians in the Mexican context. Potential stakeholders and decision makers interested in supporting the process of consolidation of family medicine, and the implementation of primary care in the country should be included. Consumer collectives need strengthening to avoid the power imbalance between health professionals and users, above all those using public services. The formation of committees of users of health services is already encouraged by authorities to oversee the performance of the health teams in institutional ambulatory care, but they have limited power to represent the community in case of complaints.

\section{Promote the Professionalization of COLMEXAC as a Legal Entity}

The Cancún Manifesto promotes the professionalization of COLMEXAC as a legal entity to achieve greater representation in the institutions and the health system itself, as part of an overall strategy of legal empowerment of primary care/family medicine organizations. Legal empowerment of COLMEXAC is absent in academic and health decisions. There is a need to transform this civil association into a college of professionals, or even better, a federation of family medicine colleges. This would increase the negotiating capacity of the College, in its position as an administrator of substantial changes in the working conditions of its members at the Mexican Social Security Institute, which constitute $95 \%$ of its membership. It would also facilitate its intervention in matters of primary care/family medicine by participating in the design of educational programs in Mexican medical schools, tailoring them to genuine health needs. An additional necessary advantage is the establishment of the College as an arbitrator in cases of allegations of negligence or other legal problems, in addition to its link with the education sector.

\section{Conclusion}

Overall, it is intended that the advancement of each of these strategies, including some which act synergistically, will effect a change in the positioning of family medicine and primary care in the Mexican health system. The definition of the responsibilities of family physicians in conjunction with the legal empowerment of COLMEXAC will strengthen the influence of this association over medical school curricula as well as the services provided by health institutions. Research on the ecology of health and care will inform strategies to reallocate resources to first level health centers and suggest lower priority to build large hospitals. The creation or strengthening of associations of users could have a positive effect on the image of family doctors although when complaints are due to a lack of equipment, medications, or other supplies, or work overload because of a personnel shortage, patients may challenge those who directly care for them, that is, doctors and nurses.

Mexico has made advances in health, but challenges remain, such as raising the efficiency and quality of health spending, ensuring greater public financing in health care, improving the quality of services, and providing universal coverage, especially in disadvantaged areas. It is possible to mobilize joint efforts to increase the role that primary care has in shaping health systems. However, Mexico is at a crossroad. Other Mexican state reforms have not been totally implemented. Structural changes in the care system are less feasible in the short run, but actions must be taken toward the implementation of strategies to make primary care the foundation of the Mexican health system.

The processes and strategies adopted by the COLMEXAC may serve as a guide and framework for other countries seeking to address health inequities and to move toward universal primary health care coverage.

To see this article online, please go to: http://jabfm.org/content/ 30/6/843.full.

\section{References}

1. Nigenda G, Wirtz V, González-Robledo L, Reich M. Evaluating the implementation of Mexico's health reform: The case of Seguro Popular. Health Systems Reform 2015;217-28.

2. Starfield B, Shi L, Macinko J. Contribution of primary care to health systems and health. Milbank Q 2005;83:457-502.

3. Starfield B. Primary care: An increasingly important contributor to effectiveness, equity, and efficiency of health services. SESPAS report 2012. Gac Sanit 2012;26(Suppl 1):20-26.

4. Frenk J, González-Pier E, Gómez-Dantés O, Lezana MA, Knaul FM. Comprehensive reform to improve 
health system performance in Mexico. Lancet 2006; 368:1524-1534.

5. van Weel C, Turnbull D, Ramirez J, et al. Supporting health reform in Mexico: Experiences and suggestions from an International Primary Health Care Conference. Ann Fam Med 2016;14:279-280.

6. Call KT, McAlpine DD, Garcia CM, et al. Barriers to care in an ethnically diverse publicly insured population: Is health care reform enough? Med Care 2014;52:720-727.

7. Chung S, Lesser LI, Lauderdale DS, Johns NE, Palaniappan LP, Luft HS. Medicare annual preventive care visits: use increased among fee-for-service patients, but many do not participate. Health Aff (Millwood) 2015;34:11-20. [Erratum in Health Aff (Millwood). 2015;34:359].

8. O'Malley JP, O'Keeffe-Rosetti M, Lowe RA, et al. Health care utilization rates after Oregon's 2008 Medicaid expansion: Within-group and betweengroup differences over time among new, returning, and continuously insured enrollees. Med Care 2016; 54:984-991.

9. World Health Organization. The World Health Report 2008: Primary health care-Now more than ever. Geneva, Switzerland: World Health Organization; 2008.

10. Goodyear-Smith F, Gauld R, Cumming J, O'Keefe $\mathrm{B}$, Pert H, McCormack P. International learning on increasing the value and effectiveness of primary care (I LIVE PC) New Zealand. J Am Board Fam Med 2012;25 Suppl 1(Suppl 1):S39-S44.

11. Phillips RL Jr. International learning on increasing the value and effectiveness of primary care (I LIVE PC). J Am Board Fam Med 2012;25 Suppl 1(Suppl 1): S2-S5.

12. van Weel C, Kassai R, Tsoi GW, et al. Evolving health policy for primary care in the Asia Pacific region. Br J Gen Pract 2016;66(647):e451-e453.

13. van Weel C, Turnbull D, Whitehead E, et al. International collaboration in innovating health systems. Ann Fam Med 2015;13:86-87.

14. Albavera Hernández C, López Caudana AE, Juárez Márquez SA, et al. Manifiesto Cancún. Ann Fam Med 2016;14:178-180.

15. Bonilla-Chacin M, Aguilera N. The Mexican Social Protection System in Health. UNICO Studies Series No. 1. 2013. Available from: http://siteresources.
worldbank.org/HEALTHNUTRITIONAND POPULATION/Images/MexicanSocialProtection SysteminHealth.pdf. Accessed Nov, 2016.

16. Organisation for Economic Co-operation and Development. Health at glance 2015. OECD indicators. 2015. Available from: http://www.oecd.org/ health/health-systems/health-at-a-glance-19991312. htm.

17. Frenk J, González-Pier E, Gómez-Dantés O, Lezana MÁ, Knaul FM. Reforma integral para mejorar el desempeño del sistema de salud en México [Comprehensive reform to improve health system performance in Mexico]. Salud Pública de México 2007; 49(Suppl 1):s23-s36.

18. Starfield B. Family medicine should shape reform, not vice versa. Fam Pract Manag 2009;16:6-7.

19. Albavera Hernandez C, Lopez Caudana AE, Juarez Marquez SA, et al. Manifesto Cancún. 2016. Available from: http://www.napcrg.org/ Resources/CancunManifesto.

20. Sociedad Española de Medicina de Familia y Comunitaria. The European definition of the general practitice/family medicine. 2007. Available from: http:// www.woncaeurope.org/sites/default/files/documents/ Wonca\%20definition\%20spanish\%20version.pdf. Accessed 21 November, 2017.

21. White KL, Williams TF, Greenberg BG. The ecology of medical care. 1961. Bull N Y Acad Med 1996;73:187-205, discussion 206-112.

22. Fryer GE, Jr., Green LA, Dovey SM, Yawn BP, Phillips RL, Lanier D. Variation in the ecology of medical care. Ann Fam Med 2003;1:81-99.

23. Shao CC, Chang CP, Chou LF, Chen TJ, Hwang SJ. The ecology of medical care in Taiwan. J Chin Med Assoc 2011;74:408-412.

24. López-Cervantes M, Durán Arenas JL, Villanueva Lozano M. La necesidad de transformar el sistema de salud en México [The need of transforming the health system in Mexico]. Gaceta Médica de México 2011;147:469-474.

25. Green LA, Fryer GE Jr, Yawn BP, Lanier D, Dovey SM. The ecology of medical care revisited. N Engl J Med 2001;344:2021-2025.

26. White KL. Two cheers for ecology. Ann Fam Med 2003;1:67-69. [Erratum in Ann Fam Med 2003;1: 179]. 